\title{
COMMENTARY \\ Faculty support is essential for success
}

Residents in primary care training programs are increasingly required by the Accreditation Council for Graduate Medical Education to have experience in community Jimmy H Hara California State Commissioner for Health Manpower Policy

Director of Graduate Medical Education Southern California Kaiser Permanente 4747 Sunset Blvd Los Angeles, CA 90027

Correspondence to: Dr Hara Jimmy.H.Hara@kp.org

West J Med

2000;172:340 medicine. ${ }^{1}$ The Family Practice Program Requirements state that residents in family practice must be taught to assess and understand the important health needs of the community in which they work. ${ }^{1}$ Internal medicine similarly requires service to that community as an important part of professionalism, and residents are encouraged to participate in community programs. Pediatric curriculums include community-oriented care involving the care of children in underserved groups, with attention to the multicultural dimensions of health care.

The Tavistock Group — a multidisciplinary group of health professionals who met in Tavistock Square in London in 1991 — recently issued a policy statement for those who shape and give health care. ${ }^{2}$ One of their five tenets states that cooperation with each other and those served is imperative for those working in the health care delivery system. In a recent treatise on innovative thinking for the improvement of medical systems, Plsek theorizes that the tools of idea generation are based on three principles: mental attention, escape, and movement. ${ }^{3}$ These are activities that help people to look at their current situations in a different way, to escape the way they usually think about things, and to support them in generating innovative, testable ideas to improve health care systems. ${ }^{3}$

The article by Miller and colleagues shows that a community needs assessment conducted by the community itself led to the development of a truly innovative project that at first blush would not have appeared to improve the health of the community. But, as the authors indicated, economic conditions and hygiene are often more important determinants of health outcomes than traditional medical or public health interventions.

Besides allocated time and didactic teaching of community organizing and cultural competency issues, a critical element for the success of projects such as this is faculty commitment. Faculty must be willing not only to support the effort but also to engage in the activity itself or in similar endeavors and to thereby serve as role models to convince residents that this type of work is worthwhile. In Los Angeles, the Venice Family Clinic and Los Angeles Free Clinic serve as community service placement sites for residents in family practice, internal medicine, pediatrics, and obstetrics and gynecology from the University of California at Los Angeles (UCLA), UCLA-Santa Monica, Cedars-Sinai, and Kaiser Permanente medical centers. The success of these partnerships reflects the level of faculty commitment and involvement. The hope is that residents who are involved in such projects will develop an ongoing commitment to community service.

References

1 Essentials of accredited residencies in graduate medical education: institution and program requirements. Graduate medical education directory, 1998-1999. Chicago: Accreditation Council for Graduate Medical Education; 1998:25-219.

2 Smith R, Hiatt H, Berwick D. A shared statement of ethical principles for those who shape and give health care: a working draft from the Tavistock Group. Ann Intern Med 1999;130:143-147.

3 Plsek P. Innovative thinking for the improvement of medical systems. Ann Intern Med 1999;131:438-444.

\section{The two sides of compassion}

In a journey of compassion what we have ultimately as our guide is whatever understanding we may have gained along the way of ourselves and others, chiefly those close to us, so close to us that we have lived daily in their sufferings. From here on, then, in the blinding smoke it is no longer a "seeing world" but a "feeling world"- the pain of others and our compassion for them.

Norman Maclean

From Young Men and Fire, Chicago: University of Chicago Press, 1992

Perhaps it's what they call "compassion fatigue," the idea that we get so much human suffering thrust in our faces every day from the media that we've become sort of numbed, we've used up all our reserves of pity, anger, outrage, and can only think of the pain in our own knee. David Lodge

From Therapy, New York: Penguin Books, 1996

\section{Correction}

In the Op-Ed by Grimes in the March issue of wjm, the correct reference citations for references 10 through 13 are:

10 IMAP statement of emergency contraception. IPPF Medical Bulletin 1994;6:1-2.

11 Piaggio G, von Hertzen H, Grimes DA, et al. Timing of emergency contraception with levonorgestrel or the Yuzpe regimen. Lancet 1999;353:721. (Task Force on Postovulatory Methods of Fertility Regulation.)

12 Cates W, Jr, Raymond EG. Emergency contraception - parsimony and prevention in the medicine cabinet. Am J Public Health 1997:87:909-910.

13 Glasier A, Baird D. The effects of self-administering emergency contraception. N Engl J Med 1998;339:1-4. 